Article

www.mdpi.com/journal/remotesensing

\title{
Evaluating Airborne Multispectral Digital Video to Differentiate Giant Salvinia from Other Features in Northeast Texas
}

\section{Reginald S. Fletcher ${ }^{1}{ }^{*}$, James H. Everitt ${ }^{1}$ and Howard S. Elder ${ }^{2}$}

1 USDA-ARS, Kika de la Garza Subtropical Agricultural Research Center, 2413 E. Hwy. 83, Weslaco, TX 78596, USA; E-Mail: james.everitt@ars.usda.gov

2 Texas Parks and Wildlife Department, Rt. 2, Box 535, Jasper, TX 75951, USA;

E-Mail: Howard.Elder@tpwd.state.tx.us

* Author to whom correspondence should be addressed; E-Mail: reginald.fletcher@ars.usda.gov; Tel.: +1-956-969-4834.

Received: 20 August 2010; in revised form: 24 September 2010 / Accepted: 13 October 2010 / Published: 19 October 2010

\begin{abstract}
Giant Salvinia (Salvinia molesta) is one of the world's most invasive aquatic weeds. We evaluated the accuracy of airborne multispectral digital video imagery for separating giant salvinia from other aquatic and terrestrial features at a study site located in northeast, Texas. The five-band multispectral digital video imagery was subjected to an unsupervised computer analysis to derive a thematic map of the infested area. User's and producer's accuracies of the giant salvinia class were $74.6 \%$ and $87.2 \%$, respectively. Aerial multispectral digital videography has potential as a remote sensing tool for differentiating giant salvinia from other terrestrial and aquatic features.
\end{abstract}

Keywords: aquatic weed; giant salvinia; digital videography; invasive weed

\section{Introduction}

According to Westbrooks [1], invasive plants are plants that have been introduced into an environment in which they did not evolve and thus usually have no natural enemies to limit their reproduction and spread. It is estimated that invasive plants cost the United States (U.S.) economy \$35 billion dollars annually, including losses and damages associated with the infestations and costs of controlling invasive plants [2]. 
Sensors onboard airborne and satellite-borne platforms have provided remotely-sensed imagery that natural resource managers can use to detect, map, and monitor invasive plant infestations [3-5]. The imagery shows "a bird's eye view" of the area of interest, aiding the analyst in evaluating the infested area. Large areas are imaged in a short period of time, reducing man hours and cost to survey large regions [6]. The sensors can obtain imagery of inaccessible areas infested with invasive plants. The imagery is a permanent record that managers can input into a geographic information database to monitor spread of the infestation over time and evaluate effectiveness of treatments used to control the infestation [7]. Investigators can subject imagery to computer analysis, leading to estimates of infested versus non-infested areas within the region of interest.

Airborne electronic multispectral imaging systems have gained popularity as tools for remotely surveying terrestrial and aquatic features. These systems offer near-real time availability of the imagery and can obtain imagery in broad and narrow regions of the electromagnetic spectrum. The latter may enhance separation of the feature of interest. To meet spectral specifications for particular missions, analysts have the luxury of employing specific filters in the cameras. These systems are also useful for studying small and noncontiguous areas affected by invasive weeds [7].

Giant Salvinia (Salvinia molesta), one of the world's most invasive aquatic weeds, is a floating, rootless aquatic fern indigenous to the coastal region of southern Brazil (between latitudes $24^{\circ} \mathrm{S}$ and $32^{\circ} \mathrm{S}$ ) [8,9]. It invades lakes, ponds, oxbows, ditches, slow flowing streams and rivers, backwater swamps, marshes, and rice fields [9]. The plant prefers freshwater and not brackish water habitats. Its rapid growth, quick vegetative reproduction, and tolerance to environmental stress (i.e., freezing air temperatures, extended periods without sunlight, and viability up to one year without water) make giant salvinia an aggressive, competitive plant that impacts aquatic environments, water use, and local economies. In natural environments, plant biomass can double in one week to ten days [10,11]. Giant salvinia affects water systems by displacing native plants, preventing light and atmospheric oxygen from entering into the water, and consuming dissolved oxygen needed by fish and other aquatic plants [11].

Giant salvinia has spread throughout the southern U.S. by independent introductions. The first giant salvinia infestation in the U.S. was found in South Carolina in 1995. Since then, it has been recorded in over 90 locations, including 41 freshwater drainage basins of Texas, Louisiana, Mississippi, Alabama, South Carolina, North Carolina, Georgia, Florida, Arizona, California, Virginia, and Hawaii [12]. In the U.S., major infestations occur in Texas and Louisiana [12]. Mechanical, chemical, and biological procedures are used to control giant salvinia infestations [13]. Natural resource managers need accurate and up-to-date information on its presence to effectively control giant salvinia within an aquatic system.

Aerial color-infrared photography and high spatial resolution multispectral satellite imagery have been used by researchers to detect and map giant salvinia infestations [14,15]. With the development of electronic camera systems and advances in digital camera technology, the commercial industry has migrated toward using these cameras instead of analog film cameras to conduct aerial surveys of the earth surface. As of October 2009, Kodak, the manufacturer of color-infrared film, discontinued Kodak Aerochrome III Infrared Film 1443 because of decreasing demand for the product [16]. This discontinuance further substantiates the importance of aerial electronic imaging systems to conduct aerial surveys. 
Satellites periodically overpass an area at a specific time. If the weather conditions are not ideal during the overpass, the image acquisition may be delayed for days, weeks, or even months. Satellite imagery is not cost effective for mapping small and noncontiguous areas. In addition, other customers' requests may have priority over your request, delaying image acquisition.

Airborne imaging systems offer flexibility for image acquisition. Data collection can occur anytime the sun is sufficiently high in the sky and on any day [7] and on partly cloudy days as long as the clouds are not covering the area of interest. Problems are also associated with these systems. The major issue is the time it takes to complete image-to-image registration, if multiple cameras are employed for data collection.

Because giant salvinia infests a variety of aquatic systems, opportunities exist for employing airborne electronic imaging systems to conduct surveys of areas infested by this invasive plant. Currently, no information is available on the application of airborne electronic imaging systems for differentiating giant salvinia from other aquatic and terrestrial features. The objective of this case study was to evaluate the accuracy of airborne multispectral digital video for separating giant salvina from other aquatic and terrestrial features at a study site located in northeast, Texas.

\section{Materials and Methods}

\subsection{Site Description}

The study was conducted at Siepe Bayou $\left(31^{\circ} 43^{\prime} \mathrm{N} 93^{\circ} 51^{\prime} \mathrm{W}\right.$, Figure 1) located in the Toledo Bend Reservoir (75,330 ha impoundment of the Sabine River located on the Texas-Louisiana border) near Huxley, Texas, USA. Giant salvinia was first detected in the reservoir in September 1999 [12] and has continued to infest it on a yearly basis. Terrestrial vegetation present at the study site (approximately $0.94 \mathrm{~km}^{2}$ ) included common woody plants composed of bald cypress [Taxodium distichum] and several species of pines (Pinus spp.) and oaks (Quercus spp.). Giant salvinia was the dominant aquatic plant. Other aquatic plants observed at the study site were alligator weed [Alternanthera philoxerodes], American lotus [Nelumbo lutea], parrotfeather [Myriophyllum aquaticum], waterhyacinth (Eichhornia crassipes), pennywort (Hydrocotyle ranunculoides), burhead [Echinodorus rostratus], smartweed (Polygonum pennsylvanicum), water primrose [Ludwigia peploides], and torpedograss (Panicum repens).

\subsection{Image Acquisition}

On June 13, 2006, aerial multispectral digital video imagery was acquired of the study site with a six-camera electronic digital video imaging system [17] mounted in a camera port in the floor of a Cessna 404 airplane. The imagery was acquired at an altitude of 3,800 $\mathrm{m}$ above ground level at approximately 1.5 hours before solar noon. At this altitude, spatial resolution of the pixels per camera was approximately $3 \mathrm{~m}$. 
Figure 1. (a) Map of the U.S. with the state of Texas highlighted in gray and (b) a map of Texas showing the location of the study site.

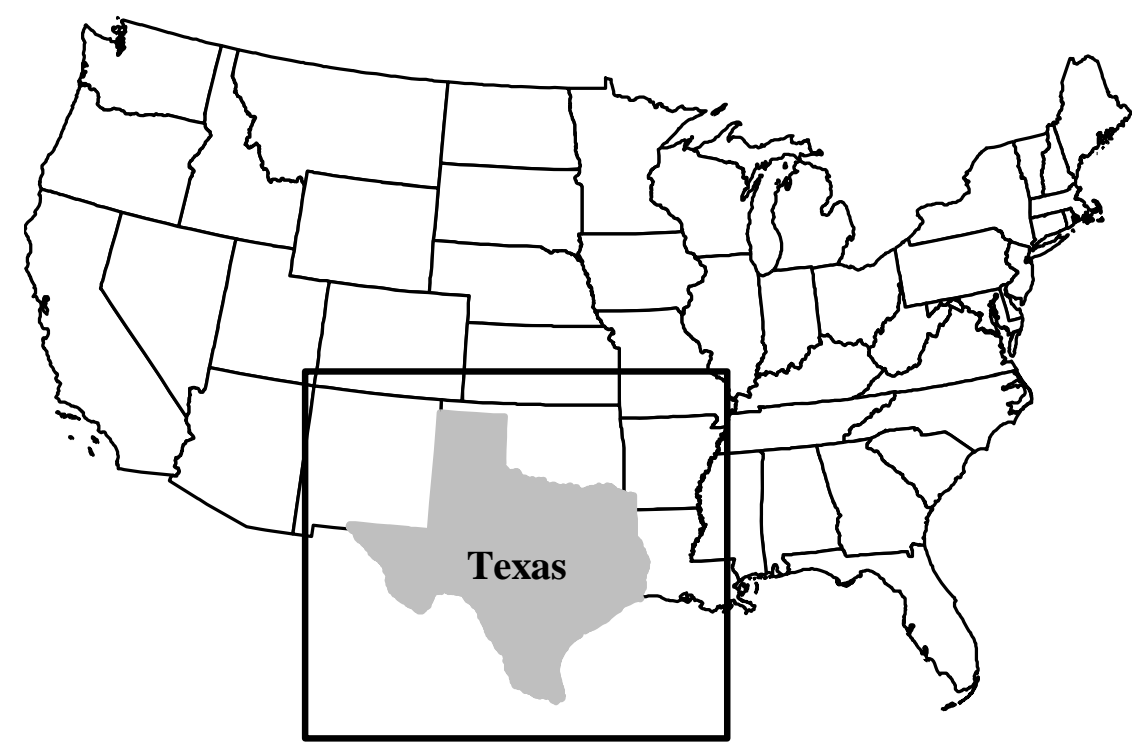

(a)

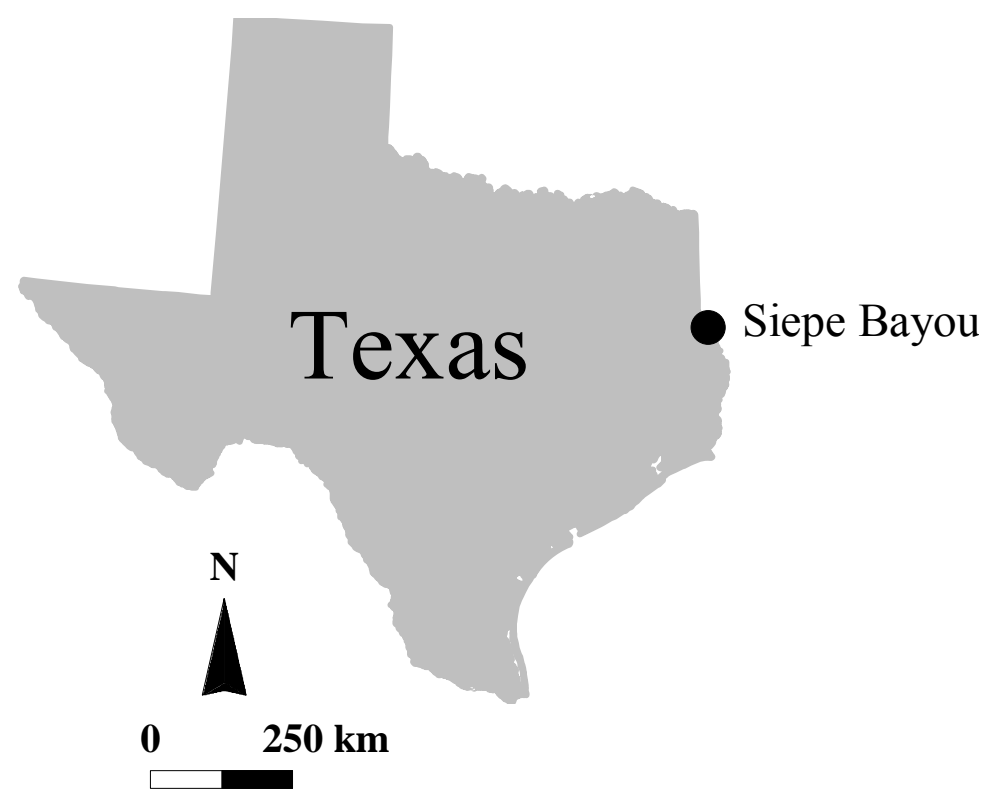

(b)

Each camera was fitted with a narrowband interference filter, allowing the system to obtain imagery in the blue $(447-455 \mathrm{~nm})$, green $(555-565 \mathrm{~nm})$, red $(625-635 \mathrm{~nm})$, red edge $(704-715 \mathrm{~nm})$, near-infrared (760-900 nm), and mid-infrared (1,531-1,576 nm) regions of the light spectrum. Analog video imagery acquired by the system is converted to digital format with a multichannel digitizing board having 640 (horizontal) by 480 (vertical) pixel resolution. The cameras have an 8-bit radiometric resolution. For more information on the system, please consult Fletcher and Everitt [17]. 


\subsection{Image Processing}

For each wavelength, an image was selected for additional analysis. The selected images were transferred to the Earth Resource Data Analysis System (ERDAS Imagine, Version 9.1) software for further processing.

Before the mission, the cameras were aligned with the technique described by Escobar et al. [18]. This procedure did not provide perfect alignment of the cameras because of their positions in the camera mount. Therefore, an image-to-image registration was performed to align selected imagery of the study area. The blue, green, near-infrared, and mid-infrared images were registered to the red image. The red edge image was not used because the camera aperture was too open during the mission, leading to overexposure of the sensor. The geocorrection tool was used to complete the image-to-image registration. A first order polynomial and the nearest neighbor interpolation method were employed for this task. Total root mean square (RMS) errors for image-to-image registrations were less than 0.5 pixels.

The aligned images were grouped into a composite file using the stack module. An image-to-map registration was employed to rectify the five-band composite image to the Universal Transverse Mercator Coordinate System (UTM north Zone 15). A georeferenced panchromatic QuickBird image of the study site was used as the map image. A first order polynomial and the nearest neighbor interpolation method were used in the rectification. The total RMS error was 1.2 pixels. The spatial resolution of the rectified five-band composite image was $3 \mathrm{~m}$.

The Iterative Self Organizing Data Analysis Technique (ISODATA) was used to conduct an unsupervised classification on the five-band composite image (group file). The algorithm employs the minimum spectral distance formula to create clusters. It generates a set of arbitrary clusters or employs means of an existing signature set as the initial cluster set. The algorithm assigns pixels within the imagery to the cluster with the nearest centroid. Then the program establishes new cluster means based on the prior iteration, and then repeats the process. The procedure continues until it reaches the maximum iteration threshold or the percentage of pixel assignments do not change based on a specified percentage between two iterations. The following options were selected in the ISODATA module: generate a set of arbitrary clusters, 600 iterations, 75 clusters, and a threshold value of one-meaning a set of arbitrary clusters were used as the initial cluster set and the process was halted when 600 iterations or a threshold value of one was obtained. The 75 clusters were visually evaluated and merged into one of four classes, giant salvinia, mixed aquatic vegetation, mixed woody vegetation, or water. Ground-truth data collected during two site visits and high resolution color-infrared transparencies (acquired the same day as the digital video imagery) were used to assist the authors in assigning the clusters to classes. To remove pixel speckling from the final thematic image, a 3 by 3 majority filter was applied using the neighborhood option of the ERDAS software.

\subsection{Accuracy Assessment}

As part of another pilot study, a thematic map of the study site was developed with airborne color-infrared photography acquired on the same day as the digital video imagery. Based on a stratified random algorithm, 150 points were selected for assessing the accuracy of that map. The land cover type at each area was identified by ground visits to the study area. The same 150 ground-truth points 
were used to check the accuracy of the thematic map derived from the five-band digital video composite and the unsupervised classification.

Statistical assessment of the thematic map consisted of error matrix analysis, incorporating overall accuracy, the kappa coefficient, and user's and producer's accuracies [19]. The overall accuracy was calculated by dividing the total number of correctly classified observations by the total number of observations. It tends to overestimate classification accuracy, since it overlooks the proportion of random agreement between datasets [19]. Therefore, the Kappa statistic was also tabulated. It measured the difference between observed agreement and chance agreement. The Kappa value was determined with the following formula: Kappa statistic $=\left(\mathrm{P}_{\mathrm{o}}-\mathrm{P}_{\mathrm{c}}\right) /\left(1-\mathrm{P}_{\mathrm{c}}\right) ; \mathrm{P}_{\mathrm{o}}$ represents true agreement, and $\mathrm{P}_{\mathrm{c}}$ equals chance agreement. The Kappa value ranges from a value of 1 to $-1: 1$ equals perfect agreement, 0 equals what would be expected by chance agreement, and negative values represent agreement less than chance agreement.

User's and producer's accuracies quantified the individual class accuracies. The former measures the probability of the point selected on the map actually represent that point on the ground; the latter measures how well points visited on the ground by the producer matches up with the map. User's accuracy was computed by dividing the total number of points correctly classified for a category by the total number of points classified as that category. Producer's accuracy was determined by dividing the total number of points correctly classified for a category by the total number of reference points for that category. The overall accuracy, the Kappa statistic, and the user's and producer's accuracies were tabulated with the accuracy assessment tool of ERDAS.

The $\mathrm{z}$ statistic was employed to determine if the thematic map was significantly different $(95 \%$ confidence interval; $\mathrm{z}$ value $=1.96 ; \alpha=0.05$ ) from a random chance classification [20]. It was calculated employing the following formula: $\mathrm{z}=$ Kappa statistic/SQRT [Variance (kappa statistic)]; $\mathrm{SQRT}=$ square root. At the $95 \%$ confidence level, the critical $\mathrm{z}$ value is 1.96 [19]. If the absolute value of the $\mathrm{z}$ statistic is greater than 1.96, then the result is significant. The $\mathrm{z}$ statistic was calculated with a Visual Basic program provided by the University of New Hampshire.

\section{Results and Discussion}

Figure 2(a) shows a conventional color composite of the study area derived with the digital video imaging system. It was created by projecting visible blue, green, and red images obtained with the system through blue, green, and red color inputs of the computer, respectively. On the imagery, the infestation appears to be well distributed throughout the study area.

The thematic map (Figure 2(a)) derived from the unsupervised classification of the five-band composite (visible, near-infrared, and mid-infrared) had an overall accuracy of $82 \%$ (Table 1). This value was slightly below the overall accuracy recommended $(85 \%)$ for a land cover classification map [21]. The Kappa value was 0.7319 , indicating the map was $73.19 \%$ (Kappa value multiplied by 100) better than a random chance classification and that a substantial agreement (0.61-0.80, [22]) occurred between reference and map data. The Kappa value also provided the opportunity to determine if the thematic map was significantly better than a random chance classification via the $z$ statistic [19]. The $\mathrm{z}$ value for this map was 16.22 , indicating that the thematic map was significantly better than a random chance classification. 
Figure 2. (a) Natural color composite of the study site. Yellow (moderate plant cover (50-75\%) - surface was a mixture of water and giant salvinia) and blue (high plant cover-giant salvinia completely masked out water surface) arrows-giant salvinia, white arrow-mixed woody vegetation, black arrow_mixed aquatic, and red arrow-water. (b) Thematic map of giant salvinia infestation at the study. Map was derived from five-band (blue, green, red, near-infrared, and mid-infrared) composite image of the study site.



(a)

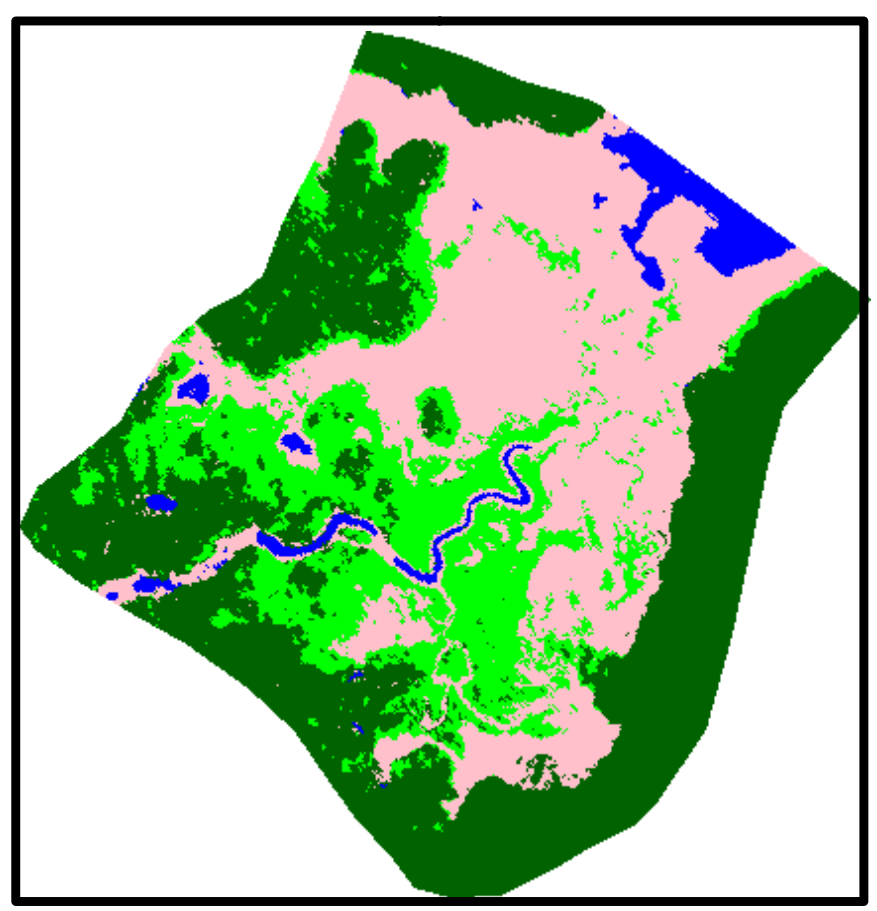

\section{Legend}

Giant Salvinia

Mixed Aquatic

Mixed Woody

Water

(b)

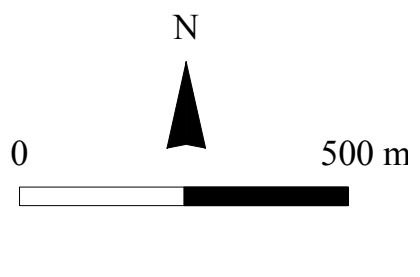


User's and producer's accuracies of the giant salvinia class were $74.6 \%$ and $87.2 \%$, respectively (Table 1). These findings indicated that $74.6 \%$ of the areas labeled giant salvinia on the map were actually giant salvina and that $87.2 \%$ of the giant salvinia class was correctly identified. Errors for the giant salvinia class were primarily attributed to it being misclassified as mixed aquatic vegetation (Table 1). Overall, these accuracies were greater than the $70 \%$ standard threshold recommended for a class on remotely-sensed maps [21], suggesting that aerial multispectral videogaphy has potential as a remote sensing tool to separate giant salvinia from other features.

From an aerial multispectral data perspective, our findings (Table 1) are comparable with those of Everitt et al. [23,24]. They used aerial color-infrared photography subjected to an unsupervised classification to map a giant salvinia infestation in southeast, Texas, and achieved user's and producer's accuracies ranging from $78.3 \%$ to $89.5 \%$ for green and senesced giant salvinia classes. Therefore, it is believed that airborne multispectral digital video imagery can serve as an adequate replacement to color-infrared photography as tool for surveying areas infested with giant salvinia.

Everitt et al. $[23,24]$ also employed a three-camera digital video imaging system to differentiate the invasive weeds waterlettuce (Pistia stratiotes), hydrilla (Hydrilla verticillata), and waterhyancinth from other aquatic and terrestrial features. User's and producer's accuracies were $76.5 \%$ and $92.9 \%$, respectively, for the waterlettuce class; $81.8 \%$ and $90 \%$, respectively, for the hydrilla class; and $84.6 \%$ for the waterhyancinth class. Their results support our findings of using aerial multispectral digital videography for separating an invasive weed from other features $[23,24]$.

Table 1. Error matrix for thematic map derived with five-band multispectral data.

\begin{tabular}{ccccccc}
\hline & & \multicolumn{5}{c}{ Reference Data } \\
Map Data & GS & MA & MW & W & Total & User's Accuracy (\%) \\
\hline GS & 41 & 14 & 0 & 0 & 55 & 74.6 \\
MA & 0 & 20 & 3 & 0 & 23 & 85.0 \\
MW & 2 & 4 & 58 & 0 & 64 & 90.6 \\
W & 4 & 0 & 0 & 4 & 8 & 50.0 \\
Total & 47 & 38 & 61 & 4 & & \\
Producer's Accuracy (\%) & 87.2 & 52.6 & 95.1 & 100 & & \\
\hline
\end{tabular}

Overall accuracy $82.0 \%$; kappa statistic $=0.7318$

${ }^{\dagger} \mathrm{GS}=$ giant salvinia, $\mathrm{MA}=$ mixed aquatic, $\mathrm{MW}=$ mixed woody, and $\mathrm{W}=$ water

Hyperspectral imaging systems collect data in many contiguous bands. Mixed results have been achieved with these systems. At a relatively fine spatial scale for five sites (average of 51 ha per site) within California's Sacramento-San Joaquin River Delta, Underwood et al. [25] using airborne hyperspectral imagery achieved average classification accuracies of $93 \%$ and $73 \%$ for Brazilian waterweed and waterhyacinth, respectively. Our mapping accuracy (user's accuracy) is similar to what they achieved for waterhyancinth and much lower than that achieved for Brazilian waterweed. Many factors can contribute to the accuracy of a classification, including spatial, spectral, and radiometric resolutions of the sensor, spectral similarities or differences among aquatic and terrestrial features, and environmental conditions (e.g., water clarity). We believe that an integration of these factors contributed to similarities and differences observed in this study compared with other studies [23-25]. 


\section{Conclusions}

Prior to this research, no information was available on using airborne electronic multispectral imagery to differentiate giant salvinia from other aquatic and terrestrial features. The overall findings indicated that airborne multispectral digital videography has potential for completing that task. Natural resource managers can use the thematic map derived with the imagery and computer analysis as a decision support tool. For example, they can employ the map to determine where to apply chemical and biological control measures.

This study was conducted in northeast Texas. More research is needed to further substantiate applications of airborne multispectral digital videography for distinguishing giant salvinia from other features at locations in Texas and throughout the world. Future studies should also focus on processing the imagery with other computer algorithms. These programs may result in the development of more accurate thematic maps. The findings of this research support further investigations of multispectral digital video and true multispectral digital imaging systems for mapping this aquatic weed and other weeds infesting aquatic systems.

\section{Acknowledgements}

The authors thank Carl Boatman, Isabel Cavazos, Rene Davis, Fred Gomez, and Juan Ramos for their assistance in this study. This project was funded by USDA-ARS; mention of trade names or commercial products in this publication is solely for the purpose of providing specific information and does not imply recommendation or endorsement by the USDA.

\section{References}

1. Westbrooks, R. Invasive Plants, Changing the Landscape of America: Fact Book; FICMNEW: Washington, DC, USA, 1998.

2. Pimentel, D.; Zuniga, R.; Morrison, D. Update on the environmental and economic costs associated with alien-invasive species in the United States. Ecol. Econ. 2005, 52, 273-288.

3. Joshi, C.M.; de Leeuw, J.; van Duren, I.C. Remote sensing and GIS applications for mapping and spatial modeling of invasive species. In Proceedings of the XXth International Society for Photogrammetry and Remote Sensing Congress: Geo-imagery Bridging Continents, Istanbul, Turkey, July 2004.

4. Lass, W.L.; Prather, T.S.; Glenn, N.F. A review of remote sensing of invasive weeds and example of the early detection of spotted knapweed (Centaurea maculosa) and babysbreath (Gypsophila paniculata) with a hyperspectral sensor. Weed Sci. 2005, 53, 242-251.

5. Madden, M. Remote sensing and geographic information system operations for vegetation mapping of invasive exotics. Weed Technol. 2004, 17, 1357-1363.

6. Strand, H.; Höft, R.; Strittholt, J.; Miles, L.; Horning, N.; Fosnight, E.; Turner, W. Sourcebook on Remote Sensing and Biodiversity Indicators; Secretariat of the Convention on Biological Diversity: Montreal, QC, Canada, 2007. 
7. Hunt, R.E.; Hamilton, R.; Everitt, J.H. Mapping weed infestations using remote sensing. Remote Sensing Applications Center, USDA Forest Service: Salt Lake City, UT, USA, 2005. Available online: http:/www.fs.fed.us/eng/rsac/invasivespecies/documents/mapping.pdf (accessed on 14 January 2010).

8. Forno, I.W.; Harley, K.L.S. The occurrence of Salvinia molesta in Brazil. Aquat. Bot. 1979, 6, 175-177.

9. Forno, I.W. Native distribution of the Salvinia auriculata complex and key to species identification. Aquat. Bot. 1983, 16, 71-83.

10. Mitchell, D.S. The incidence and management of Salvinia molesta in Papua New Guinea; Draft Report; Office Environmental Conservation and Department of Primary Industry: Komedobu, Papau New Guinea, 1979.

11. Thomas, P.A.; Room, P.M. Taxonomy and control of Salvinia molesta. Nature 1986, 319, 581-584.

12. Jacono, C.C.; Richerson, M.M. Salvinia molesta Progression, 2004. Available online: http://salvinia.er.usgs.gov/index.html (accessed on 19 January 2010).

13. McFarland, D.G.; Nelson, L.S.; Grodowitz, M.J.; Smart, R.M.; Owens, C.S. Salvinia molesta D. S. Mitchell (Giant Salvinia) in the United States: A Review of Species Ecology and Approaches to Management; Final Report; Aquatic Plant Control Research Program, United States Army Corps of Engineers: Washington, DC, USA, 2004.

14. Everitt, J.H.; Yang. C.; Helton, R.J.; Hartmann L.H.; Davis, M.R. Remote sensing of giant salvinia in Texas waterways. J. Aquatic Plant Manage. 2002, 40, 10-15.

15. Everitt, J.H.; Fletcher, R.S.; Elder, H.; Yang. C. Mapping giant salvinia with satellite imagery and image analysis. Environ. Monit. Assess. 2008, 129, 35-40.

16. Eastman Kodak Company. Discontinued product: Kodak Aerochrome III Infrared Film 1443. Kodak News October 19, 2009; F6.

17. Fletcher, R.S.; Everitt, J.H. A six-camera digital video imaging system sensitive to visible, red edge, near-infrared, and mid-infrared wavelengths. Geocarto Int. 2007, 22, 75-86.

18. Escobar, D.E.; Everitt, J.H.; Noriega, J.R.; Davis, M.; Cavazos, I. A true digital imaging system for remote sensing applications. In Proceedings of the 15th Biennial Workshop on Videography and Color Photogrpah in Resource Assessment, Weslaco, TX, USA, 1997.

19. Congalton, R.; Green, K. Assessing the Accuracy of Remotely Sensed Data: Principles and Practices; CRC/Lewis Press: Boca Raton, FL, USA, 1999.

20. Rosenfield, G.; Fitzpatrick-Lins, S. A coefficient of agreement as a measure of thematic classification accuracy. Photogramm. Eng. Remote Sensing 1986, 52, 223-227.

21. Thomlinson, J.R.; Bolstad, P.V.; Cohen, W.B. Coordinating methodologies for scaling landcover classifications from site-specific to global: Steps toward validating global map products. Remote Sens. Environ. 1999, 70, 15-28.

22. Landis, J.; Koch, G. The measurement of observed agreement for categorical data. Biometrics. 1977, 33, 149-164.

23. Everitt, J.H.; Yang, C.; Escobar, D.E.; Webster, C.F.; Lonard, R.I.; Davis, M.R. Using remote sensing and spatial information technologies to detect and map two aquatic macrophytes. $J$. Aquat. Plant Manage. 1999, 37, 71-80. 
24. Everitt, J.H.; Yang, C.; Flores, D. Light reflectance characteristics and remote sensing of waterlettuce. J. Aquat. Plant Manage. 2003, 41, 10-15.

25. Underwood, E.C.; Mulitsch, M.J.; Greenberg, J.A.; Whiting, M.L.; Ustin, S.L.; Kefauver, S.C. Mapping invasive aquatic vegetation in the Sacramento-San Joaquin Delta using hyperspectral imagery. Environ. Monit. Assess. 2006, 111, 47-64.

(C) 2010 by the authors; licensee MDPI, Basel, Switzerland. This article is an open access article distributed under the terms and conditions of the Creative Commons Attribution license (http://creativecommons.org/licenses/by/3.0/). 